\title{
Newborn screening for cystic fibrosis: Polish 4 years' experience with CFTR sequencing strategy
}

\author{
Agnieszka Sobczyńska-Tomaszewska ${ }^{\star, 1,2,5}$, Mariusz Ołtarzewski ${ }^{1,5}$, Kamila Czerska ${ }^{1,2}$, Katarzyna Wertheim- \\ Tysarowska $^{1,2}$, Dorota Sands ${ }^{1}$, Jarosław Walkowiak ${ }^{3,4}$, Jerzy Bal ${ }^{1}$, Tadeusz Mazurczak ${ }^{1}$ and NBS CF working group ${ }^{6}$
}

Newborn screening for cystic fibrosis (NBS CF) in Poland was started in September 2006. Summary from 4 years' experience is presented in this study. The immunoreactive trypsin/DNA sequencing strategy was implemented. The group of 1212487 newborns were screened for cystic fibrosis during the programme. We identified a total of 221 CF cases during this period, including, 4 CF cases were reported to be omitted by NBS CF. Disease incidence in Poland based on the programme results was estimated as $1 / 4394$ and carrier frequency as $1 / 33$. The frequency of the F508del was similar (62\%) to population data previously reported. This strategy allowed us to identify 29 affected infants with rare genotypes. The frequency of some mutations (eg, 2184insA, K710X) was assessed in Poland for the first time. Thus, sequencing assay seems to be accurate method for screening programme using blood spots in the Polish population.

European Journal of Human Genetics (2013) 21, 391-396; doi:10.1038/ejhg.2012.180; published online 15 August 2012

Keywords: cystic fibrosis; gene mutation; screening-newborn; screening

\section{INTRODUCTION}

Cystic fibrosis (CF) is one of the most common life-shortening autosomal recessive diseases in Caucasian population, affecting about 1 person in every 2500-3500. ${ }^{1}$ Previously, the incidence of CF in Poland equalled $1 / 2500$ as calculated on the basis of the available epidemiological data. ${ }^{2}$ However, only 1440 CF patients in Poland (of over 38 million inhabitants) were registered in Polish Cystic Fibrosis Registry (data from 30 September 2010). ${ }^{3}$ According to the Wisconsin Cystic Fibrosis Neonatal Screening Study Group and others, ${ }^{4,5}$ newborn screening for CF (NBS CF) provides an immediate and accurate diagnosis, often before the onset of clinical symptoms and is associated with significantly improved physical development and a lower prevalence of lung infections. Neonatal screening for CF has been widely implemented and accepted, however, ethical aspects with regard to possible benefits and risks are still a matter of debate. ${ }^{6}$

CF screening programmes are based on the immunoreactive trypsin (IRT) assay on dried blood spots. ${ }^{7}$ The elevated levels of IRT have a relatively poor positive predictive value in the neonatal period, therefore earlier protocols relied on a second sample to confirm the initial screening result (IRT/IRT protocol), ${ }^{8}$ thereby enhancing sensitivity of affected newborn detection during the NBS CF to $80 \%{ }^{9}$ The identification of the CFTR gene and pathogenic mutations subsequently have opened a gateway for the genetic testing of the DNA from the original blood spot. A two-tier neonatal screening programme (IRT/DNA) was first performed in South Australia in 1989. ${ }^{10}$ Furthermore, a reduction of molecular techniques costs has allowed the possibility of direct gene analysis as a second analytic stage in many national screening programmes. Unfortunately, in the CFTR gene (188kb, 27 exons) nearly two thousand sequencing variants have been identified to date (precise count for 31 October 2011: 1893 according to the CFTR Mutation Database, http://www.genet.sickkids.on.ca/app). The relative frequencies of mutations vary in different ethnic groups and populations ${ }^{11}$. Only one mutation, the F508del accounts for $\sim 70 \%$ of CFTR mutant alleles in Europe but this also differs between populations. ${ }^{12,13}$ In Polish CF patients the frequency of the F508del mutation is estimated as $53-57 \% .^{14,15}$

According to the a panel of the most frequent mutations in Polish CF patients published in $2009^{16}$ and our personal experience (unpublished data), mutations such as K710X and 2184insA have a frequency $>0.45 \%$. As these sequence variants, are not included in commercial assays (eg, InnoLipa Innogenetics, CF assay Abbott, Tepnel Diagnostics Elucigene), we decided to apply the direct sequencing of selected CFTR gene regions as part of the genetic protocol of NBS CF, in order to avoid the poor effectiveness of the IRT/DNA protocol using commercial kits.

The first pilot NBS CF study was introduced in Poland in 1999 and continued until 2002, covering one-quarter of the Polish population. ${ }^{17}$ The current programme was implemented in 2006 and was expanded to cover whole country in summer 2009 (Figure 1a).

The aim of this summary is to evaluate the strategy of the NBS CF programme in Poland with respect to the usefulness of the DNA sequencing, as well as to revise the panel of most frequent CFTR mutations in the Polish population.

\footnotetext{
${ }^{1}$ Institute of Mother and Child, Kasprzaka, Warsaw, Poland; ${ }^{2}$ Health Care Centre GENOMED, Ponczowa, Warsaw, Poland; ${ }^{3}$ Ist Chair of Pediatrics, Department of Gastroenterology and Metabolism, Poznan University of Medical Sciences, Szpitalna, Poznan, Poland; ${ }^{4}$ Department of Dietetics, Poznan University of Life Sciences, Wojska Polskiego, Poznan, Poland

*Correspondence: Dr A Sobczyńska-Tomaszewska, Health Care Center GENOMED, Ponczowa 12, 02-971 Warsaw, Poland. Tel: + $48516156290 ;$ Fax + 4822 644 6025 ; E-mail: agnieszkasobtom@gmail.com

${ }^{5}$ These authors contributed equally to this work

${ }^{6}$ Members of the NBS CF working group in alphabetical order are given in Appendix.

Received 12 March 2012; revised 30 May 2012; accepted 13 July 2012; published online 15 August 2012
} 
a

\begin{tabular}{|c|c|c|}
\hline $\begin{array}{l}\text { Period of NBS } \\
\text { CF }\end{array}$ & Method & $\begin{array}{l}\text { The most frequent mutations in Polish population } \\
\text { under analysis }\end{array}$ \\
\hline $\begin{array}{l}\text { September } 2006 \\
\text { - December } 2007\end{array}$ & $\begin{array}{ll}\text { Estonia Asper Biotech } & \text { E } \\
\text { assay } & 11 \\
& \mathrm{R} \\
15 \\
\mathrm{Q} \\
1 \varepsilon \\
2 \\
32 \\
35 \\
\mathrm{~N}\end{array}$ & $\begin{array}{l}\text { E60X, G85E, 394delTT, R117H, R117P, R117L, } \\
\text { I148T, 621G>A, 711+1G>T, 711+5G>A, 1078delT, } \\
\text { R334W, R347H, R347P, R347L, IVS8-T, A455E, } \\
\text { I507del, F508del, 1717-1G>A, G542X, p.G551D, } \\
\text { Q552X, R553X, R553G, R560T, R560K, 1898+1G>A, } \\
\text { 1898+1G>T, 1898+1G>C, 2143delT, 2184delA, } \\
\text { 2183AA>G, 2789+5G>A, 3120+1G>A, 3199del6, } \\
\text { 3272-26A>G, R1162X, 3659delC, 3849+10kbC>T, } \\
\text { 3905insT, S1235R, S1251N, W1282X, W1282C, } \\
\text { N1303K, CFTRdele2,3 }\end{array}$ \\
\hline $\begin{array}{l}\text { January } 2007 \\
\text { - June } 2009\end{array}$ & $\begin{array}{l}\text { Sanger sequencing of } \\
\text { exons: } 4,7,10,11,13 \text {, } \\
21 \text {, fragment of intron } \\
19\end{array}$ & $\begin{array}{l}\text { F508del, CFTRdele2,3, 3849+10kbC>T, } \\
\text { R117H+IVS8- }{ }^{*}, \text { R334W, R347P, 1717-1G >A, } \\
\text { G542X, R553X, K710X, 2184insA, 2143delT, } \\
\text { 2183AA>G, N1303K }\end{array}$ \\
\hline $\begin{array}{l}\text { July } 2009 \\
\text { - currently }\end{array}$ & $\begin{array}{l}\text { Sanger sequencing of } \\
\text { exons: } 7,10,11,13 \text {, } \\
\text { 17b, } 20,21 \text {, fragment of } \\
\text { intron } 19\end{array}$ & $\begin{array}{l}\text { F508del, CFTRdele2,3, 3849+10kbC>T, R334W, } \\
\text { R347P, 1717-1G>A, G542X, R553X, K710X, } \\
\text { of } 2184 \text { ins A, 2143delT, 2183AA>G, N1303K, 3272- } \\
\text { 26A>G**, W1282X** }\end{array}$ \\
\hline
\end{tabular}

b

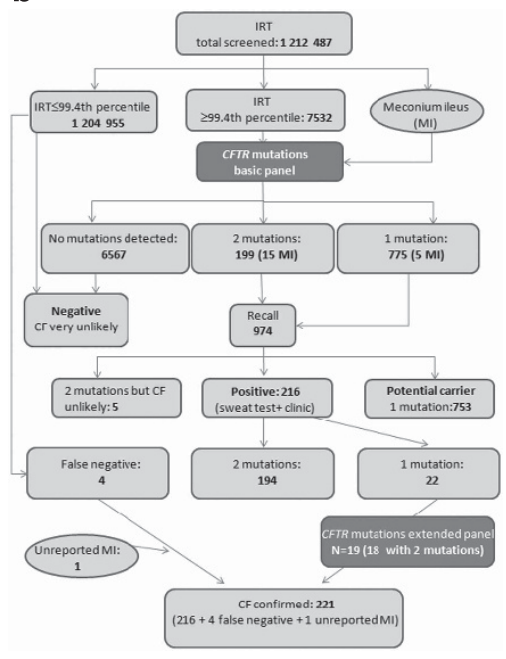

Figure 1 NBS CF in Poland. (a) Spectrum of mutations analysed; (b) strategy and summary of obtained results.

\section{PATIENTS AND METHODS}

\section{Study population}

The study group includes neonates born between September 2006 to December 2010. The screening programme was gradually introduced into Polish territory and since the summer of 2009, all neonates born in Poland have been included into NBS CF programme. A total of 1212487 newborns were screened for CF.

\section{IRT analysis protocol}

IRT was measured in dried blood spot samples from neonates (aged 3-5 days). To determine an IRT concentration $(\mathrm{ng} / \mathrm{ml})$, the IRT Neonatal Screening ELISA colorimetric assay (IBL International, Hamburg, Germany) was used. According to results from the pilot NBS CF programme completed in 2002, the IRT concentration cutoff was established as $>99.4$ percentile. In addition in all neonates with meconium ileus (MI), the DNA analysis was performed regardless of IRT value.

\section{DNA analysis}

Genomic DNA was eluted from two 3-mm diamater discs using the Extract Blood PCR Kit (Sigma Aldrich, St Louis, MO, USA). According to the Polish Society of Cystic Fibrosis recommendation, ${ }^{16}$ for the purpose of NBS CF, a panel of the CFTR gene mutations showed in Figure la was implemented. This panel and the examined regions of the CFTR gene were slightly altered during the screening programme.

The selected CFTR gene regions (Figure 1a) were analysed by direct sequencing. PCR and sequencing primers were either made as described previously ${ }^{18}$ or designed with the Primer 3 software (Geeknet Inc., Fairfax, VA, USA). The presence of the CFTRdele2,3 mutation was determined according to Dörk et al ${ }^{19}$ PCR reaction mix and conditions are available on request. PCR products were purified using EXOSAP-IT (USB Corporation, Cleveland, OH, USA) according to the manufacturer's protocol. Standard sequencing reaction and capillary electrophoresis using ABI PRISM 3730 sequencer (Applied Biosystems, Life Technologies Corporation, Carlsbad, CA, USA) were performed. Fluorochromatograms were analysed using the Mutation Surveyor software (SoftGenetics, State College, PA, USA). Sequence NM_000492.3 was used as a reference. Novel mutations were analysed with prediction module of Alamut version 1.53 software (Interactive Biosoftware, Rouen, France). The CFTR mutations nomenclature is consistent with the CFTR Mutation Database legacy names (http://www.genet.sickkids.on.ca). Other databases used in the study were as follows: NCBI (http://www.ncbi. nlm.nih.gov), Ensembl (http://www.ensembl.org/index.html), 1000 Genomes (http://www.1000genomes.org) and HGMD Professional (https://portal.biobaseinternational.com/hgmd, http://www.hgmd.cf.ac.uk/ac/index.php).

\section{Clinical confirmation of $\mathrm{CF}$}

Neonates with one or two identified mutations were referred directly for clinical assessment and a sweat test at the age of 3-4 weeks to CF Centres in Poland (eight centres). The sweat tests were performed by the classic Gibson and Cook method and Nanoduct method parallely. ${ }^{20}$ The diagnosis of CF was established according to recommendations. ${ }^{16}$ Parents of neonates that were identified as affected or carriers were suggested genetic counselling and were offered genetic testing.

\section{RESULTS}

During a screening project lasting over 4 years, more than one million newborns were screened (Figure $1 \mathrm{~b}$ ). For each positive IRT result (>99.4 percentile) direct CFTR gene analysis was performed by sequencing of selected regions. The complete analysis using this diagnostic panel allowed us to identify (1) nearly $80 \%$ of the mutated alleles in Poland and (2) mutations in one or both alleles in nearly 95\% of screened CF patients (according to frequency data published by Bobadilla et $a l^{15}$ ). Blood trypsin values above the threshold were found in 7532 neonates. After biochemical, genetic and clinical evaluation, 216 affected subjects (194 genotyped and 22 with 1 mutation identified so far) were identified in the NBS CF programme. This group includes 20 cases of (MI; 9.3\%, 20/216). In addition, one newborn with MI did not have any genetic analyses performed, because information about MI was not printed on the screening card and IRT was below the cutoff for IRT. This newborn had CFTR molecular analysis performed at the age of 2.5 years (genotype: [F508del];[F508del]) due to clinical symptoms. So far (until March 2012) we have had information about four cases of false-negative results in NBS CF (Table 1). Thus, the total number of CF cases identified in the period of NBS CF in Poland is 221 (216 from NBS CF, 4 omitted by NBS CF and 1 with unreported MI).

In five other children, despite two CFTR mutations detected, a clinical evaluation did not confirm the presence of CF. These newborns had the CFTR genotype as follows: [F508del];[D537N], [F508del];[P731L], [F508del];[T1053I] (two unrelated newborns) and [F508del];[L467F]. Mutations D537N and P731L have not been 
Table 1 Characteristic of the cases omitted in the screening for CF programme owing to IRT values $<99.4$ percentile

\begin{tabular}{|c|c|c|c|c|}
\hline Newborn & $\begin{array}{l}\text { Patients' genotype after } \\
\text { first stage CFTR analysis }\end{array}$ & $\begin{array}{l}\text { Sweat test (pilocarpine } \\
\text { ionthoforesis (mmol/l)) }\end{array}$ & Clinical history & $\begin{array}{l}\text { Patients' genotype after extended CFTR } \\
\text { analysis (performed on physician's request; } \\
\text { sequencing of entire coding region) }\end{array}$ \\
\hline 1 & {$[2183 A A>G] ;[=]$} & $116 ; 139$ & Recurrent diarrhoea, pneumonia, liver dysfunction & {$[2183 \mathrm{AA}>\mathrm{G}] ;[\mathrm{E} 92 \mathrm{~K}]$} \\
\hline 2 & {$[$ F508del $] ;[=]$} & $80 ; 127 ; 136$ & Chronic diarrhoea, failure to thrive, pneumonia & [F508del];[4218insT] \\
\hline 3 & {$[=] ;[=]$} & $118 ; 140$ & Pneumonia, liver dysfunction & {$[Q 207 X] ;[=]$} \\
\hline 4 & {$[=] ;[=]$} & 56 & Diarrhoea, pneumonia & [L997F];[1210-12T[5] + 1210-13G > T] ${ }^{\mathrm{b}}$ \\
\hline
\end{tabular}

Abbreviations: CF, cystic fibrosis; IRT, immunoreactive trypsin; NBS CF, newborn screening for CF; =, no mutation identified.

${ }^{a}$ The analysis covered the same mutation panel as in the case of NBS CF.

${ }^{b} \operatorname{cs} 3 G>T=I V S 8-5 T+(T G) 13$.

Table 2 Genotypes of CF newborns with mutations not included into common commercial kits applied in Poland and European countries*

\begin{tabular}{|c|c|}
\hline Genotype & Number of cases \\
\hline [F508del]; [1767-8T>A*] & 1 \\
\hline [F508del];[2184insA*] & 6 \\
\hline [F508del];[E33X*] & 1 \\
\hline [F508del];[F1286C*] & 1 \\
\hline [F508del];[G314R*] & 1 \\
\hline [F508del];[K710X*] & 1 \\
\hline [F508del];[W1282R*] & 1 \\
\hline$\left[\right.$ F508del];[1898+1G $\left.>C^{*}\right]$ & 1 \\
\hline [F508del];[3600 + 2insT*] & 1 \\
\hline [F508del];[F1052V*] & 1 \\
\hline [F508del];[V1240G*] & 1 \\
\hline [F508del];[T582I*] & 1 \\
\hline [2143delT];[R1102X*] & 1 \\
\hline [2143delT];[2721del11*] & 1 \\
\hline$[3272-26 \mathrm{~A}>\mathrm{G}] ;\left[\mathrm{K} 967 \mathrm{~S}^{*}\right]$ & 1 \\
\hline [CFTRdele2,3];[Y1092X*] & 1 \\
\hline$\left[K 710 X^{*}\right] ;\left[K 710 X^{*}\right]$ & 1 \\
\hline$\left[\mathrm{L} 32 \mathrm{X}^{*}\right] ;\left[3600+2 \mathrm{insT}^{*}\right]$ & 1 \\
\hline [N1303K];[2184insA*] & 1 \\
\hline [N1303L];[T1036I*] & 1 \\
\hline [R553X];[3182ins8*] & 1 \\
\hline [2143delT];[V1240G*] & 1 \\
\hline [R553X];[Trp356X*] & 1 \\
\hline [L997F*];[1210-12T[5];1210-13G > T] & 1 \\
\hline Total & 29 \\
\hline
\end{tabular}

reported to the CFTR Mutation Database so far. Beside these two, several other new defects not registered in the CFTR Mutation Database were detected as well as rare mutations that were not included into commercial assays (Tables 2 and 3).

The strategy based on sequencing of CFTR regions implemented into NBS CF allowed us to identify a full genotype for 29 newborns (13\% of all identified CF cases), which could not be detected by other routinely used molecular methods (Table 2). In addition, in 22 subjects, extended CFTR genetic analysis was suggested owing to abnormal or borderline sweat tests results and clinical suspicion of CF.

The pathogenicy status of novel and rare missense variants was assessed by bioinformatic analysis using the Alamut software. This programme evaluates effect of particular sequence variations using PolyPhen, Align-GVGD and SIFT alghoritms. The D537N variant in exon 11 was designated as possibly pathogenic and P731L as possibly
Table 3 Frequency of CFTR mutations in Polish CF patients from newborns screening programme

\begin{tabular}{|c|c|c|c|}
\hline \multicolumn{2}{|c|}{ CFTR mutations } & \multirow{2}{*}{$\begin{array}{c}\text { Frequency } \\
\text { according to } \\
\text { Bobadilla et al } \\
\%\end{array}$} & \multirow{2}{*}{$\begin{array}{c}\text { Frequency according to } \\
\qquad \begin{array}{c}\text { NBS CF results } \\
\text { (all }=442 \text { CF alleles) } \\
\%\end{array}\end{array}$} \\
\hline Name & Position & & \\
\hline F508del & Exon11 & 57.1 & 62.4 \\
\hline $3849+10 \mathrm{kbC}>\mathrm{T}$ & Intron 22 & 2.7 & 3.0 \\
\hline G542X & Exon 12 & 2.6 & 1.6 \\
\hline $1717-1 \mathrm{G}>\mathrm{A}$ & Intron 11 & 2.4 & 1.4 \\
\hline R553X & Exon 12 & 1.9 & 2.5 \\
\hline CFTRdele2,3 & Exons 2 and 3 & 1.8 & 6.2 \\
\hline N1303K & Exon 24 & 1.8 & 2.1 \\
\hline 2143delT & Exon 14 & No data & 2.8 \\
\hline 2184insA & Exon 14 & No data & 1.8 \\
\hline $2183 A A>G$ & Exon 14 & No data & 1.6 \\
\hline W1282X & Exon 23 & 0.7 & 1.5 \\
\hline R334W & Exon 8 & No data & 0.7 \\
\hline R347P & Exon 8 & No data & 0.5 \\
\hline G551D & Exon 12 & 0.5 & 0.0 \\
\hline K710X & Exon 14 & No data & 0.7 \\
\hline $3272-26 A>G$ & Intron 19 & No data & 0.7 \\
\hline $3600+2$ ins $T$ & Intron 21 & No data & 0.5 \\
\hline $1898+1 G>C$ & Intron 13 & No data & 0.5 \\
\hline V1240G & Exon 23 & No data & 0.5 \\
\hline Others $^{a}$ & - & No data & 10.0 \\
\hline
\end{tabular}

Abbreviations: $\mathrm{CF}$, cystic fibrosis; NBS CF, newborn screening for CF.

a Mutations not included into common commercial kits.

tolerated. Of note, in the case of some other changes, the results were unclear - for example, in the case of already known mutations published in the CFTR Mutation Database: T1053I (according to Align-GVGD: 'less likely to be pathogenic', score C0, PolyPhen: 'possible damaging', score 0.816 and SIFT: 'deleterious', score 0.01 ), similarly for L467F (Align-GVGD: 'less likely', class C0, PolyPhen: 'probably damaging', score 0.994 and SIFT: 'deleterious', score 0.03).

The evaluation of the most frequent CFTR mutations in the Polish population in examined gene regions showed that three additional mutations reached our adopted cutoff ( $0.45 \%$ of frequency): $3600+$ 2insT, $1898+1 \mathrm{G}>\mathrm{C}$ and V1240G (Table 3). We assumed that during the period of the NBS CF programme, we detected all F508del homozygotes (90/221 cases, $41 \%$ ). Based on this assumption, the previously published data of the frequency of this mutation in the Polish population $\left(57 \%,{ }^{15}\right)$, the data from the Polish Cystic Fibrosis Patients Registry ${ }^{3}(56-62 \%)$ and the results of the clinical follow-up 
ending in December 2011, we calculated the CF incidence in our country as $1 / 4394$ and carrier frequency as $1 / 33$. The incidence and carrier frequency are lower (1/5249:5486 and 1/36:37, respectively) when results from NBS CF are taken into account.

\section{DISCUSSION}

The screening programme for $\mathrm{CF}$ has been implemented for many years in the Europe, USA and Australia despite the discussion over its benefits and risks. ${ }^{21}$ Here, we present the first summary of the NBS CF in Poland based on the IRT and sequencing of selected CFTR fragments.

Our NBS CF strategy lead to the diagnosis of CF in 216 neonates. The DNA analysis protocol implemented here focused on regions containing the most frequent mutations in the Polish population covering almost $80 \%$ of mutated alleles. The 90 F508del homozygotes $(41 \%)$ were identified during the period of the NBS $\mathrm{CF}$ programme and this percentage is in a large convergence with data from the Polish Cystic Fibrosis Registry (38\%, according to Stężowska-Kubiak ${ }^{3}$ ).

In recent years, the population analysis data are often used for the recalculation of the CF incidence and CFTR mutation carriership. However, the significance of these values is questionable due to the extent of false-negative results, and the incompleteness of data. This particulary important within the first years of a screening programme, when clinical follow-ups are continued. The incidence of the CF in Poland calculated on the number of F508del homozygotes and the previously reported F508del allele frequency ${ }^{15}$ would be 1/4394. The incidence of disease estimated directly on basis of the NBS CF programme results is 1 per $5248-5486$. In past, in the 1970s this parameter has been generally defined in Poland as $1 / 2500$, however, in study of Bozkowa et al selection of examined groups was not accurately matched to disease prevalence calculation. CF prevalence is more difficult to ascertain for a number of reasons, such as different medical and scientific data from published literature and from patient registries. The results of other screening programmes also show a lower incidence of the disease, than traditionally adopted $1 / 2500 .{ }^{22}$ Data from European countries, published in 2008 point an interregional variation as well (Table 4). ${ }^{23}$ Similarly, The American College of Medical Genetics with American College of Obstetricians and Gynaecologists published summary from 8 years of CF testing and estimated carrier frequency as $1 / 37.6$ in the tested panethnic population, which allows to calculate the CF frequency as $1 / 5655 .^{24}$

It is probable that the incidence of the disease in Poland is lower than the value declared in the 70s, however, its precise calculation can only be possible when the results of the NBS CF programme are summarized with the addition of clinical follow-up. We also cannot rule out that more patients have been omitted by NBS CF, like the four cases reported in this study. According to Fritz formula, ${ }^{9}$ the predicted false-negative rate for the Polish population is 6-7 cases per year, which gives 1-2 omitted CF cases per 100000 live births. After a longer follow-up, some children that are currently defined as carriers would turn out to be affected with rather mild CF or CFTRrelated diseases. In addition, according to the tendency of a smaller family model $(2+1)$ in Europe $^{25}$ and prenatal screening, ${ }^{26}$ a lower prevalence of the disease will probably be observed in the future. Such tendencies have already been observed. ${ }^{27,28}$

Beside analytical and statistical limitations, another possible reason is the under representation of children with MI. In our study, the newborns with MI only represent 9.3\%, while the literature data shows about $10-20 \%$. In neonates with MI, normal values of the IRT
Table 4 Incidence of CF in selected European country from the literature, national $\mathrm{CF}$ registries and personal information from CF leaders in Europe (according to Farrell, ${ }^{23}$ modified)

\begin{tabular}{lc}
\hline Country & CF incidence \\
\hline Austria & $1: 3500$ \\
Belgium & $1: 2850$ \\
Bulgaria & $1: 2500$ \\
Czech Republic & $1: 2833$ \\
Denmark & $1: 4700$ \\
Estonia & $1: 4500$ \\
France & $1: 4700$ \\
Germany & $1: 3300$ \\
Greece & $1: 3500$ \\
Italy & $1: 4238$ \\
Netherlands & $1: 4750$ \\
Slovakia & $1: 1800$ \\
Slovenia & $1: 3000$ \\
Sweden & $1: 5600$ \\
Poland & $1: 5000$ \\
& $1: 4394$ (from this study)
\end{tabular}

Abbreviation: CF, cystic fibrosis

are often observed. ${ }^{21}$ Such newborns could have obtained a falsenegative result of IRT and had not been redirected for genetic testing.

By preparing a newborn screening programme in Poland, we collected information about the CFTR mutations detected in Polish CF patients that are recognized on the basis of the clinical outcome (data from The Polish Cystic Fibrosis Registry and Bobadilla et $\mathrm{ll}^{15}$ ). According to these data, the F508del frequency was estimated as ;56-62\%. The frequency of the F508del allele in this group is similar to the value calculated from the NBS CF programme $(62 \%)$ and previously published data ${ }^{15}$ (57\%). Data from the Polish registry were used to designate the CFTR gene mutations and to prepare a 'Polish assay' with mutations such as K710X and 2184insA. The exonic 2184insA mutation in addition to others (eg, CFTRdele2,3, 3849+10kbC $>\mathrm{T}$ ) occurs more frequently in Central and Eastern Europe. ${ }^{29}$ Thus, the main reason for the application of our strategy was the diversity of mutations in the Polish population, for which commercial tests are not suited (Tables 2 and 3). An extended molecular analysis revealed that $3600+2$ ins $T$, mutations in loci $1898+1(\mathrm{G}>\mathrm{C}$ or $\mathrm{G}>\mathrm{A}$ ) were detected in two and three cases of CF children with extended analysis (thus $>$ cut off $0.45 \%$ of mutated alleles detected in NBS CF). These variants, together with V1240G (two alleles, frequency $>0.45 \%$ ) may therefore be candidates for a first line NBS CF molecular test panel in future. However, these results should be confirmed on a larger sample in subsequent years of NBS CF.

A selective CFTR gene scanning strategy was also used in other populations. ${ }^{30}$ An additional advantage of such diagnostic procedure is its ability to discover new or ultra-rare CFTR alleles. Indeed, we discovered about 30 sequence variants unreported previously.

We realize that the discovery of new defects is not always beneficial owing to interpretational controversies. In example, the detection of a sporadic missense variants (eg, D537N, P731L), still do not provide a clear answer to the biological and clinical significance of the defect. The D537N variant was designated as possibly pathogenic by bioinformatic analysis, whereas the P731L was designated as 'tolerated'. Both variants were detected in the 
newborns (current ages: 3 years 2 months and 1 year 5 months, respectively), that had the F508del mutation identified in the second allele, and sweat chloride concentration 14.9 and $31.2 \mathrm{mmol} / \mathrm{l}$, respectively. Until now, the disease based on clinical data has not been confirmed in these children. However, at this time, we cannot exclude the possible development of an atypical CF or CFTR-related disorders (eg, CBAVD - both children are males).

A similar problem was observed while detecting rare known mutations published in the CFTR Mutation Database. For example, the diagnosis of $\mathrm{CF}$ has not been confirmed following the identification of the T1053I and L467F mutations. As this is common problem in the NBS CF programmes, the term 'CFTR-related metabolic syndrome' was proposed. ${ }^{31}$

Dorfman et $a l^{32}$ in his work concluded that none of the current generation of in silico software accurately predicted the clinical severity of the CFTR mutations in a reliable way. Therefore, each bioinformatic analysis performed by us only served as an indicator rather than a conclusive diagnostic marker. However, new genotypephenotype relations are still being discovered that may lead to the requalification of a mutational status. For example, the I148T variant no longer has the qualification of a pathogenic mutation but is still included in the commercial kits (eg, InnoLipa, Innogenetics). ${ }^{33}$ Prudence is therefore always essential in molecular genetics.

Our experience shows that DNA protocol based on sequencing method is an efficient screening strategy in Poland. In addition to issues described above, this approach seems to be highly cost-effective considering the fact that, there is no need to repeat the analysis of exons examined during NBS CF programme, if extension of the CFTR gene analysis is necessary. However, the limitations of the IRT/DNA test should not be forgotten and each patient with signs or symptoms of $\mathrm{CF}$ should be referred to the CF centre for standard diagnostic procedure.

In summary, to our knowledge, this is the world's first full description of a CF newborn screening strategy based on IRT/DNAextended genetic analysis method, recently recommended by the Clinical and Laboratory Standards Institute. ${ }^{34}$

\section{CONFLICT OF INTEREST}

The authors declare no conflict of interest.

\section{ACKNOWLEDGEMENTS}

This work was supported by the Polish Ministry of Health. We acknowledge the contribution of Mrs Aleksandra Pęciło, Iwona Hass-Lisowska from the Institute Mother and Child and Dr Robert Crayton from the Department of General, Oncological and Functional Urology, Medical University of Warsaw whose professional assistance was invaluable in preparing analysis and writing this manuscript.

1 Kosorok MR, Wei WH, Farrell PM: The incidence of cystic fibrosis. Stat Med 1996; 15 : 449-462.

2 Bozkowa K, Golebiowska H, Rutkowski J, Nowakowska A, Holzer J: Epidemiology of muscoviscidosis in children in Poland. Pediatr Pol 1971; 46: 677-684.

3 Stężowska-Kubiak S: Clinical and epidemiological characteristics of the Polish cystic fibrosis patients. (Doctoral dissertation in Polish). University of Medical Sciences, Poznań, 2001

4 Farrell PM, Kosorok MR, Rock MJ et al: Early diagnosis of cystic fibrosis through neonatal screening prevents severe malnutrition and improves long-term growth. Wisconsin Cystic Fibrosis Neonatal Screening Study Group. Pediatrics 2001; 107: $1-13$.

5 Hale JE, Parad RB, Dorkin HL et al: Cystic fibrosis newborn screening: using experience to optimize the screening algorithm. J Inherit Metab Dis 2010; 33: (Suppl 2): S255-S261.
6 Simpson N, Anderson R, Sassi F et al: The cost-effectiveness of neonatal screening for cystic fibrosis: an analysis of alternative scenarios using a decision model. Cost Eff Resour Alloc 2005; 3: 8.

7 Ryley HC, Robinson PG, Yamashiro Y, Bradley DM: Assay of serum immunoreactive trypsin in dried blood spots and the early detection of cystic fibrosis. J Clin Pathol 1981; 34: 906-910.

8 Wilcken B, Wiley V, Sherry G, Bayliss U: Neonatal screening for cystic fibrosis: a comparison of two strategies for case detection in 1.2 million babies. J Pediatr 1995; 127: 965-970.

9 Fritz A, Farrell $P$ : Estimating the annual number of false negative cystic fibrosis newborn screening tests. Pediatr Pulmonol 2011; 47: 207-208.

10 Ranieri E, Ryall RG, Morris CP et al: Neonatal screening strategy for cystic fibrosis using immunoreactive trypsinogen and direct gene analysis. BMJ 1991; 302: 1237-1240.

11 The Molecular Genetic Epidemiology of Cystic Fibrosis. Report of a joint meeting of WHO/ECFTN/ICF(M)A/ECFS, 2002.

12 Kerem E, Corey M, Kerem BS et al: The relation between genotype and phenotype in cystic fibrosis - analysis of the most common mutation (delta F508). N Engl J Med 1990; 323: 1517-1522.

13 Scheffer H, Bruinvels DJ, te Meerman GJ et al: Frequency of the delta F508 mutation and XV2c,KM19 haplotypes in cystic fibrosis families from The Netherlands: haplotypes without delta F508 still in disequilibrium. Hum Genet 1990; 85: 425-427.

14 Aznarez I, Bal J, Casals T et al: Analysis of mutations in the CFTR gene in patients diagnosed with cystic fibrosis in Poland. Med Wieku Rozwoj 2000; 4: 149-159.

15 Bobadilla JL, Macek Jr M, Fine JP, Farrell PM: Cystic fibrosis: a worldwide analysis of CFTR mutations - correlation with incidence data and application to screening. Hum Mutat 2002; 19: 575-606.

16 Walkowiak J, Pogorzelski A, Sands D et al: Guidelines of diagnosis and treatment of cystic fibrosis. Recommendation of the Polish society of Cystic Fibrosis. Standardy Medyczne/Pediatria 2009; 6: 352-378.

17 Ołtarzewski M, Szymborski J, Sands D, Nowakowska A, Milanowski A: Optimalisation of the neonatal screening for cystic fibrosis for Polish population, 24th European Cystic Fibrosis Conference, Vienna, Austria, 2001 p37.

18 Zielenski J, Rozmahel R, Bozon D et al: Genomic DNA sequence of the cystic fibrosis transmembrane conductance regulator (CFTR) gene. Genomics 1991; 10: 214-228.

19 Dörk T, Macek Jr M, Mekus F et al: Characterization of a novel 21-kb deletion, CFTRdele2,3(21 kb), in the CFTR gene: a cystic fibrosis mutation of Slavic origin common in Central and East Europe. Hum Genet 2000; 106: 259-268.

20 Sands D, Ołtarzewski M, Nowakowska A, Zybert K: Bilateral sweat tests with two different methods as a part of cystic fibrosis newborn screening (CF NBS) protocol and additional quality control. Folia Histochem Cytobiol 2010; 48: 358-365.

21 Castellani C, Southern KW, Brownlee $\mathrm{K}$ et al: European best practice guidelines for cystic fibrosis neonatal screening. J Cyst Fibros 2009; 8: 153-173.

22 Loeber JG: Neonatal screening in Europe; the situation in 2004. J Inherit Metab Dis 2007; 30: 430-438.

23 Farrell PM: The prevalence of cystic fibrosis in the European Union. J Cyst Fibros 2008; 7: 450-453.

24 Strom CM, Crossley B, Buller-Buerkle A et al: Cystic fibrosis testing 8 years on: lessons learned from carrier screening and sequencing analysis. Genet Med 2011; 13: $166-172$.

25 Pearce D, Cantisani G, Laihonen A: Changes in fertility and family sizes in Europe. Popul Trends 1999; 95: 33-40

26 Dupuis A, Hamilton D, Cole DE, Corey M: Cystic fibrosis birth rates in Canada: a decreasing trend since the onset of genetic testing. J Pediatr 2005; 147: 312-315.

27 Hale JE, Parad RB, Comeau AM: Newborn screening showing decreasing incidence of cystic fibrosis. N Engl J Med 2008; 358: 973-974.

28 Grody WW, Cutting GR, Klinger KW, Richards CS, Watson MS, Desnick RJ: Subcommittee on Cystic Fibrosis Screening, Accreditation of Genetic Services Committee, ACMG. American College of Medical Genetics. Laboratory standards and guidelines for population-based cystic fibrosis carrier screening. Genet Med 2001; 3. 149-154.

29 Makukh $\mathrm{H}$, Krenková $\mathrm{P}$, Tyrkus $\mathrm{M}$ et al: A high frequency of the cystic fibrosis 2184insA mutation in Western Ukraine: genotype-phenotype correlations, relevance for newborn screening and genetic testing. J Cyst Fibros 2010; 9: 371-375.

30 Férec $C$, Verlingue $C$, Parent $P$ et al: Neonatal screening for cystic fibrosis: result of a pilot study using both immunoreactive trypsinogen and cystic fibrosis gene mutation analyses. Hum Genet 1995: 96: 542-548.

31 Cystic Fibrosis FoundationBorowitz D, Parad RB et al: Cystic Fibrosis Foundation practice guidelines for the management of infants with cystic fibrosis transmembrane conductance regulator-related metabolic syndrome during the first two years of life and beyond. J Pediatr 2009; 155:(6 Suppl): S106-S116.

32 Dorfman R, Nalpathamkalam T, Taylor C et al: Do common in silico tools predict the clinical consequences of amino-acid substitutions in the CFTR gene? Clin Genet 2010; 77: 464-473.

33 Dequeker E, Stuhrmann M, Morris MA et al: Best practice guidelines for molecular genetic diagnosis of cystic fibrosis and CFTR-related disorders - updated European recommendations. Eur J Hum Genet 2009; 17: 51-65.

34 Farrell P: CLSI Publishes New Guideline: Newborn Screening for Cystic FibrosisApproved Guideline. University of Wisconsin School University of Wisconsin School of Medicine and Public Health, 2011. 


\section{APPENDIX}

On behalf of the NBS CF working group:

M Bartnicka-Trawińska (Health Care Specialist Centre of the Mother and Child, Gdansk), M Gos, V Hryniewicz, M Jurek, M Nawara, K Niepokój, R Piotrowski, G Święćkowski, J Wasiluk, T Zajkowski, K Zybert, A Norek (Institute of Mother and Child, Kasprzaka 17a, 01-211 Warsaw), T Jagiełło, D Popielarz, M Rozwadowska, M Sienkiewicz, A Szpecht-Potocka (Health Care Centre GENOMED, Ponczowa 12, 02-971 Warsaw), Z Kurtyka (Regional Children's Hospital the specialist, St Louis, Cracow),

A Lisowska (Ist Chair of Paediatrics, Department of Gastroenterology and Metabolism, Poznan University of Medical Sciences, Poznan), I Ostrowska, M Giżewska (Department of Paediatrics, Endocrinology, Diabetes, Metabolic and Cardiologic Diseases of Developmental Age, Pomeranian Medical University, Szczecin), J Pawłowicz (Non-public Health Care Centre 4med, Wroclaw), T RuszczykBilecka (Nicolas Copernicus' Regional Specialist Hospital, Lodz), D Sielska-Rotblum (The Children's Memorial Health Institute, Warsaw), H Woś (Department of Paediatrics, Silesia Child Health Centre, Katowice). 